\title{
Evaluation of Factors Associated with Increased Dairy Cow Mortality on United States Dairy Operations
}

\author{
C. S. McConnel, ${ }^{* 1}$ J. E. Lombard, ${ }^{*} \dagger$ B. A. Wagner, $\dagger$ and F. B. Garry ${ }^{\star}$ \\ *Integrated Livestock Management, Colorado State University, Fort Collins 80523 \\ †USDA:APHIS:VS, Centers for Epidemiology and Animal Health, 2150 Centre Ave., Bldg. B, Fort Collins, CO 80526-8117
}

\begin{abstract}
Dairy cow mortality is an increasingly severe problem for the US dairy industry. The objective of this study was to examine a variety of herd management practices and herd characteristics to identify factors associated with increased cow mortality in US dairy herds. The National Animal Health Monitoring System's Dairy 2002 study surveyed dairy operations in 21 major dairy states. The complete data set included results from 953 dairy farms with a minimum of 30 dairy cows per farm. Associations between dairy cow mortality and 119 a priori-selected management practices or characteristics of 953 operations were evaluated. Eighty of the 119 risk factors explored in a univariate analysis met initial inclusion criteria for further evaluation of association with dairy cow mortality. A multivariable analysis was conducted to explore more complex relationships. The final multivariable model included 7 representative variables: herd levels of respiratory disease, lameness, and antibiotic use for treating sick cows, the percentage of culled cows less than $50 \mathrm{~d}$ in milk, the average calving interval, the use of a total mixed ration, and the region of the country. Increased odds of a greater level of mortality on farms was associated with greater percentages of lameness, respiratory disease, and sick cows treated with antibiotics, demonstrating the influence of physical derangements and disease on dairy cow mortality. Increased odds of a greater level of mortality was also associated with feeding a total mixed ration, culling fewer cows in early lactation, and herds located in western, midwestern, and southeastern regions relative to the northeastern United States, pointing to the importance of management decisions and operation characteristics on mortality outcomes. Further, an important interplay between facets of health and management on dairy cow mortality was suggested through the inclusion of the calving interval, with a longer calving inter-
\end{abstract}

Received June 12, 2007.

Accepted December 10, 2007.

${ }^{1}$ Corresponding author: craigmcc@lamar.colostate.edu val leading to increased odds of a greater level of mortality on farms. Analysis of a variety of herd characteristics and practices with nationally representative data suggests that several health problems in tandem with aspects of operational construct and management are associated with increasing mortality.

Key words: mortality, risk factor, dairy, cow

\section{INTRODUCTION}

Dairy cow mortality causes financial losses and is an important animal welfare issue (Thomsen et al., 2006). Results from the USDA:APHIS:VS National Animal Health Monitoring System (NAHMS) Dairy 2002 survey reported that $4.8 \%$ of dairy cows die on-farm across the country each year (USDA, 2002a). This level of mortality represents an increase from $3.8 \%$ of the January 1996 inventory, and is a relatively high death rate compared with that of beef cows or feedlot animals for which annual death rates are estimated at 1 to $1.5 \%$ (NAHMS, 1997; USDA, 2000). Dairy Herd Improvement Association records from the late 1990s suggest that dairy cow death rates are even higher. A study of 11,259 DHIA cow records ending in 1998, from all regions except the West, reported death rates of 5.9 to $7.7 \%$ (Smith et al., 2000). Variability in causes of death and rates of occurrence on different operations arises because of the complex nature of dairy management systems. In the NAHMS survey "unknown reasons" accounted for the single largest percentage (20\%) of producer-attributed reasons for dairy cow deaths, followed by calving difficulty problems (17\%), mastitis (17\%), and lameness or injury (14\%; USDA, 2002a).

Dairy cow survival is influenced by both management and genetic factors (Weigel et al., 2003). Cows that are genetically superior milk producers tend to be genetically less superior for fertility and survival (Dematawewa and Berger, 1998). Thus, with large increases in daily milk production the ability to convert energy reserves to production may be at the expense of cow health and reproduction (Lucy, 2001; Dechow et al., 2004; Tsuruta et al., 2005). Increased average yields in milk, fat, and protein have occurred alongside associ- 
ated increases in reproductive and metabolic diseases (Dechow et al., 2004). Some subclinical physiologic or metabolic problems may increase the likelihood of death. Numerous such problems have been described and can be identified including subclinical hypocalcemia, subacute ruminal acidosis, severe negative energy balance and other metabolic disease in early lactation, trace mineral and vitamin deficiency, poor immune responsiveness in the postpartum period, and feed quality problems that induce gastrointestinal disturbances or specific toxicoses (Politis et al., 1996; Mallard et al., 1998; Piccinini et al., 2004). Other clinically recognizable health problems that increase the risk of death or culling in dairy cows include calving difficulty, coliform mastitis, clinical hypocalcemia, and paratuberculosis (Dohoo and Martin, 1984; Milian-Suazo et al., 1989; Wenz et al., 2001).

There are complex genetic and phenotypic relationships among yield, fertility, and survival. Management decisions and other variables contribute to the complexity of the relationships. Although cows with the genetic potential for high production appear to have a lower genetic potential for survival, producers may provide better management (e.g., feed and health care) for those high-producing cows. Such preferential treatment may lower mortality rates for high-yielding cows relative to those for low-yielding cows (Dematawewa and Berger, 1998) and lead to a decrease in mortality with increasing milk production at the herd level (Smith et al., 2000; Thomsen et al., 2006). Nonetheless, as producers adopt new and more intensive production methods in an effort to lower costs and increase yields, systematic problems with animal care may arise, particularly in herds in which less individual attention is possible (Norgaard et al., 1999). As herds continue to expand, it is becoming increasingly important to identify factors that affect the health and survival of high-producing dairy cows (Weigel et al., 2003). The objective of this study was to examine a variety of herd management practices and herd characteristics to identify risk factors associated with increased cow mortality in US dairy herds.

\section{MATERIALS AND METHODS}

During the NAHMS Dairy 2002 study, data were collected from farms in 21 states that represented $82.8 \%$ of US dairy operations and $85.5 \%$ of the US dairy cow population. Regions and states included in the study were: West $=$ California, Colorado, Idaho, New Mexico, Texas, and Washington; Midwest = Illinois, Indiana, Iowa, Michigan, Minnesota, Missouri, Ohio, and Wisconsin; Northeast = New York, Pennsylvania, and Vermont; Southeast = Florida, Kentucky, Tennessee, and Virginia. During the first phase of this study a general management questionnaire was administered to dairy farms with one or more dairy cows on January 1 , 2002. Only farms that participated in phase I and had 30 or more dairy cows were eligible to participate in phase II. The phase II questionnaires covered topics including general management, animal health, herd characteristics, handling of manure and waste treatment, milking procedures, biosecurity, and cattle inventory. Of the 1,008 operations completing phase II, 953 had complete data and were eligible for inclusion in the analysis.

The survey design was a stratified random sample with unequal selection probabilities within each stratum. The unequal selection probabilities were implemented to ensure that large dairy operations were represented in the sample. Weights were created for each operation to account for the selection probabilities and for nonresponse. Complete details of the study design and sample weighting are published elsewhere (USDA, $2002 b)$. Continuous variables were classified into categories based on the lowest $25 \%$, middle $50 \%$, and highest $25 \%$.

The association between dairy cow mortality and 119 a priori operation-level management practices or characteristics was evaluated univariately via a Chi-square test. The percentage of dairy cow mortalities was determined by dividing the number of cows that died during 2001 by the number of dairy cows (both dry and in milk) present on January 1, 2002, for each operation (Figure 1). Mortality levels were categorized into low, moderate, and high groups $(<2.5,2.5$ to 6.25 , and $>6.25 \%)$ to be used as the outcome variables in the analysis. Independent variables that met the univariate screening criteria $(P<0.15)$ were evaluated using an unweighted ordinal logistic regression with stepwise model selection using the ologit procedure of STATA (STATA 9.2, Statacorp, College Station, TX). A second ordinal logistic model was constructed because the statistical software did not allow for a stepwise selection method that accounted for the study design and weighting. After the variable selection procedure in the first model, variables with $P<0.05$ were entered into an ordinal logistic procedure that incorporated the study design and the sampling weights to appropriately estimate model coefficients and associated standard errors. Interactions between the final selected variables were evaluated as well.

\section{RESULTS}

Eighty of the 119 risk factors explored in the univariate analysis met initial screening criteria for further evaluation of association with dairy cow mortality (Table 1). Region of the country and adult herd size were 


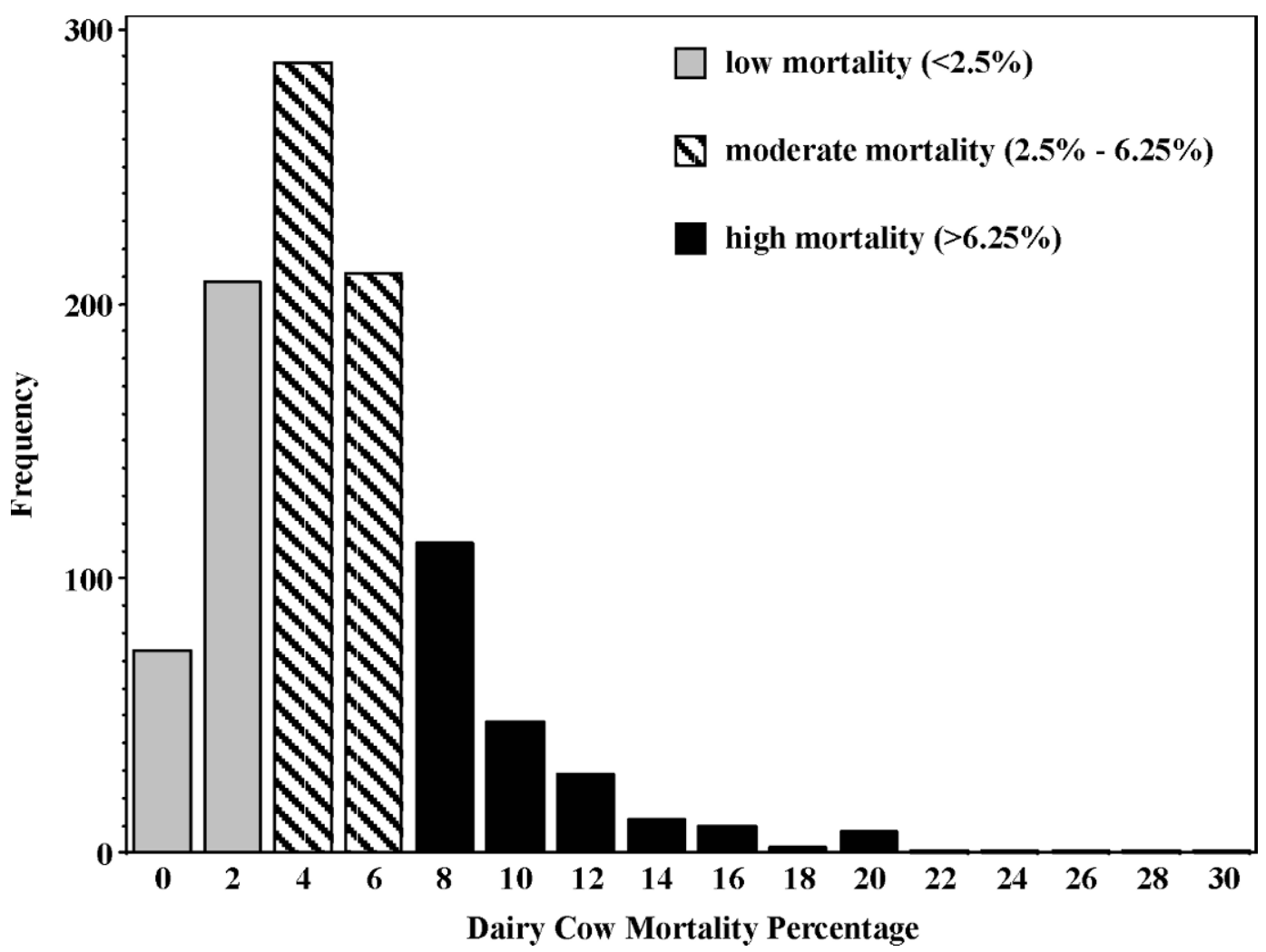

Figure 1. The frequency distribution of annual herd-level dairy cow mortality on United States dairies (n = 953 farms) for 2001 (USDA, $2002 \mathrm{a})$, categorized into low $(<2.5 \%)$, moderate $(2.5$ to $6.25 \%)$, and high $(>6.25 \%)$ groups.

associated with dairy cow mortality. Operations reporting greater than 355 adult cows were associated with increased levels of mortality $(P<0.0001$; Table 1$)$, as were those operations in the West, Midwest, and Southeast relative to the Northeast $(P=0.0002)$. A greater rolling herd average milk production $(>9,980$ $\mathrm{kg} / \mathrm{cow}$ per year) was associated with greater levels of mortality $(P<0.05)$. Other management practices such as feeding a TMR $(71.1 \%$ of operations; $P<0.0001)$, using forage test results to balance rations $(87.1 \%$ of operations; $P<0.0001$ ), using MUN to determine ration composition ( $33.5 \%$ of operations; $P=0.0002$ ), administering bST (36.4\% of operations; $P<0.0001$ ), and routine drenching of fresh cows (25.8\% of operations; $P=$ 0.0292 ) were all associated with a greater level of mortality.

Numerous health management variables describing heifer and cow vaccinations and nutritional supplementation were associated with increased levels of mortality $(P<0.05$; Table 1$)$. Variables describing herd levels of disease and illness demonstrated increased levels of mortality with increased levels of disease problems ( $P$ $<0.05$; Table 1). Specifically, reproductive problems such as greater levels of abortion, retained placentas, and other reproductive problems (e.g., dystocia, metritis) were all associated with increased mortality levels. Similar increases in mortality were observed with increased levels of respiratory problems, lameness, diarrhea, displaced abomasums, and clinical mastitis.

Various parameters describing operation facilities were associated with mortality levels. Greater levels of mortality were associated with the use of freestalls as the primary housing facility for lactating dairy cows (53\% of operations; $P<0.0001$ ), and with herds that did not provide an outside area for lactating dairy cows (30.6\% of operations; $P=0.0125$ ). If the primary housing facility for maternity cows was a multiple-animal area (43.1\% of operations), then there was an association with increased mortality levels $(P<0.0001)$. Conversely, operations primarily housing maternity cows in an individual animal area (26.2\% of operations) were associated with reduced levels of mortality $(P=0.0121)$. For variables related to biosecurity, dairies that brought cattle onto the operation were associated with increased levels of mortality $(P=0.0007)$.

Of the 80 variables that passed the screening process, only 7 that were significantly associated with mortality level at the univariate level remained in the final 
Table 1. Herd management variables associated $(P<0.15)$ with dairy cow mortality by univariate analysis of data from 953 operations in 21 states

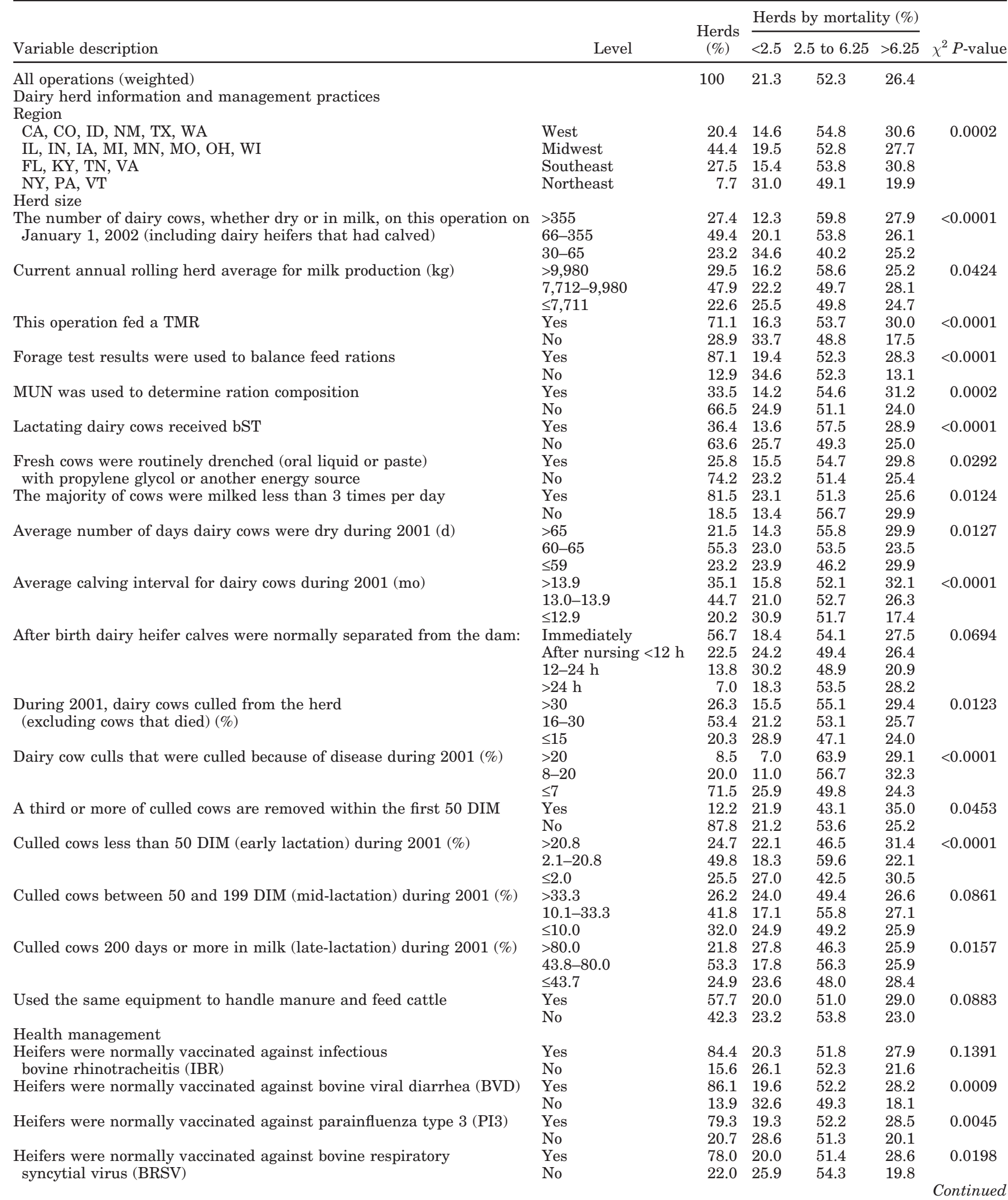


Table 1 (Continued). Herd management variables associated $(P<0.15)$ with dairy cow mortality by univariate analysis of data from 953 operations in 21 states

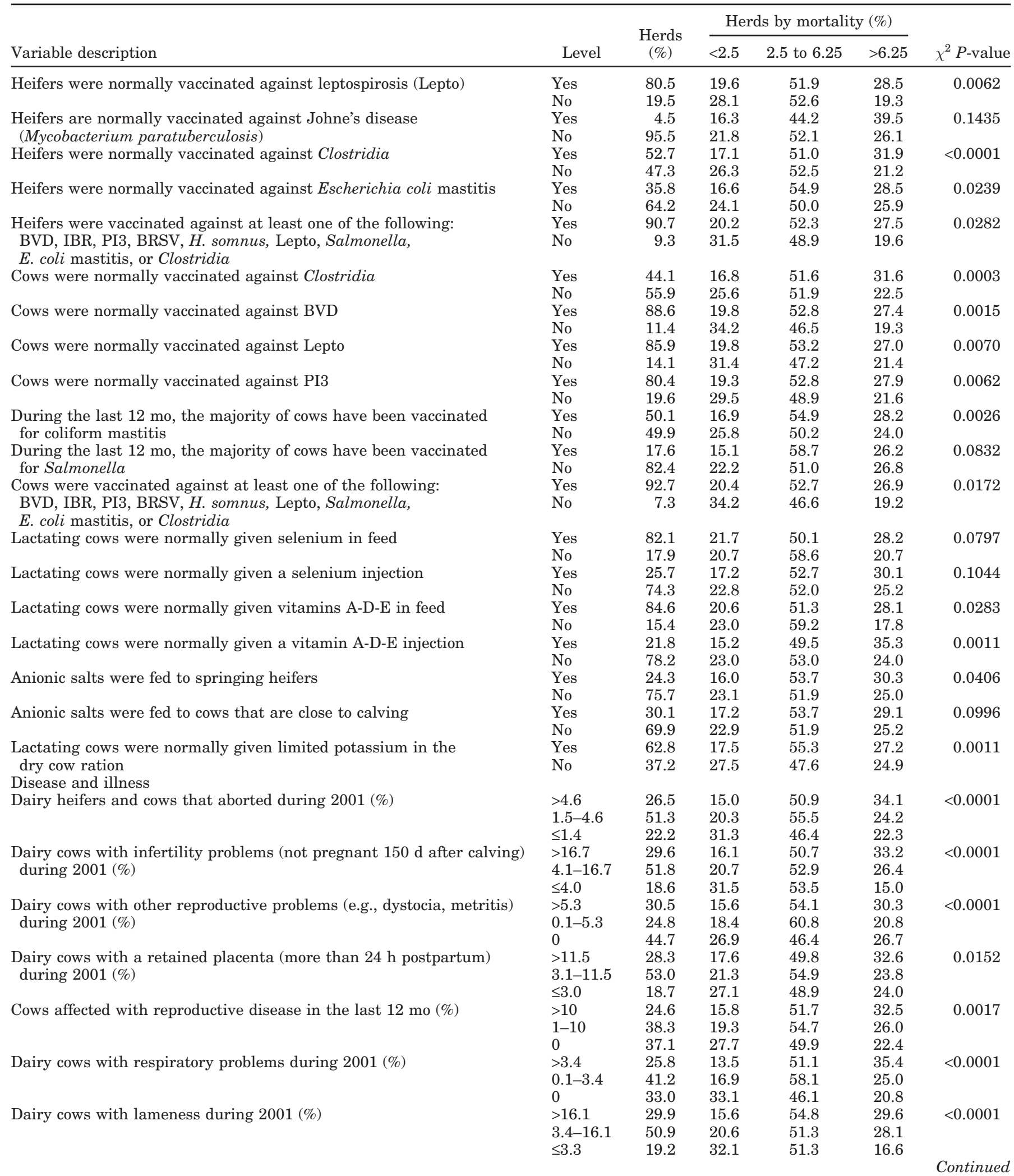


Table 1 (Continued). Herd management variables associated $(P<0.15)$ with dairy cow mortality by univariate analysis of data from 953 operations in 21 states

\begin{tabular}{|c|c|c|c|c|c|c|}
\hline \multirow[b]{2}{*}{ Variable description } & \multirow[b]{2}{*}{ Level } & \multirow{2}{*}{$\begin{array}{c}\text { Herds } \\
(\%)\end{array}$} & \multicolumn{3}{|c|}{ Herds by mortality $(\%)$} & \multirow[b]{2}{*}{$\chi^{2} P$-value } \\
\hline & & & $<2.5$ & 2.5 to 6.25 & $>6.25$ & \\
\hline \multirow[t]{2}{*}{ Dairy cows with diarrhea for more than 48 hours during $2001(\%)$} & $>2.9$ & 26.9 & 15.5 & 55.0 & 29.5 & \multirow[t]{2}{*}{0.0013} \\
\hline & & 47.0 & 27.1 & 48.6 & 24.3 & \\
\hline \multirow{3}{*}{$\begin{array}{l}\text { Cows affected with diarrhea or other digestive disease in the last } \\
12 \mathrm{mo}(\%)\end{array}$} & $>5.2$ & 24.8 & 16.1 & 52.1 & 31.8 & \multirow[t]{3}{*}{0.0446} \\
\hline & $0.1-5.2$ & 27.0 & 21.3 & 51.7 & 27.0 & \\
\hline & 0 & 48.2 & 24.5 & 52.3 & 23.2 & \\
\hline & 0 & 64.5 & 24.3 & 52.2 & 23.5 & 0.0410 \\
\hline \multirow[t]{3}{*}{ Dairy cows with a displaced abomasum during $2001(\%)$} & $>5.2$ & 28.7 & 15.2 & 53.3 & 31.5 & \multirow[t]{3}{*}{0.0002} \\
\hline & $0.1-5.2$ & 49.4 & 20.9 & 52.4 & 26.7 & \\
\hline & 0 & 21.9 & 30.5 & 50.9 & 18.6 & \\
\hline \multirow{3}{*}{$\begin{array}{l}\text { Dairy cows with clinical mastitis (presence of abnormal milk and/or } \\
\text { inflamed udder) during } 2001(\%)\end{array}$} & $>20$ & 26.2 & 17.1 & 52.6 & 30.3 & \multirow[t]{3}{*}{0.0306} \\
\hline & $7-20$ & 53.5 & 21.0 & 52.5 & 26.5 & \\
\hline & $\leq 6$ & 20.3 & 27.9 & 51.5 & 20.6 & \\
\hline Affected/sick cows that were treated at least once with antibiotics for any & $>41.2$ & 24.9 & 13.8 & 53.3 & 32.9 & 0.0003 \\
\hline disease or disorder in the last $12 \mathrm{mo}$, not including dry cow treatments or & $12.8-41.2$ & 50.1 & 22.6 & 50.6 & 26.8 & \\
\hline preventative treatments $(\%)$ & $\leq 12.7$ & 25.0 & 27.0 & 54.8 & 18.2 & \\
\hline Facilities & & & & & & \\
\hline During 2001 the primary outside area for lactating dairy cows was a drylot & Yes & 36.7 & 18.2 & 55.3 & 26.5 & 0.1473 \\
\hline & No & 63.3 & 23.2 & 50.6 & 26.2 & \\
\hline During 2001 the primary outside area for lactating dairy cows was on pasture & Yes & 32.7 & 29.8 & 48.3 & 21.9 & $<0.0001$ \\
\hline & No & 67.3 & 17.3 & 54.2 & 28.5 & \\
\hline During 2001 the primary housing facility for lactating dairy cows was a tie stall & Yes & 26.7 & 34.1 & 43.4 & 22.5 & $<0.0001$ \\
\hline or stanchion & No & 73.3 & 16.6 & 55.6 & 27.8 & \\
\hline During 2001 the primary housing facility for lactating dairy cows was & Yes & 53.0 & 15.8 & 55.4 & 28.8 & $<0.0001$ \\
\hline a free stall & No & 47.0 & 27.4 & 49.0 & 23.6 & \\
\hline During 2001 lactating dairy cows did not have an outside area & Yes & 30.6 & 16.2 & 52.9 & 30.9 & 0.0125 \\
\hline & No & 69.4 & 23.6 & 52.0 & 24.4 & \\
\hline stanchion & No & 91.8 & 19.9 & 53.8 & 26.3 & \\
\hline Maternity housing was separate from housing used for lactating dairy cows & Yes & 74.2 & 18.6 & 53.7 & 27.7 & 0.0013 \\
\hline & No & 25.8 & 29.2 & 48.1 & 22.7 & \\
\hline Separated cows that were close to calving from other dry cows & Yes & 76.7 & 19.4 & 53.2 & 27.4 & 0.0223 \\
\hline & No & 23.3 & 27.6 & 49.4 & 23.0 & \\
\hline In the winter the ground or flooring that lactating cows stand on was dry most of & Yes & 33.6 & 27.3 & 47.5 & 25.2 & 0.0033 \\
\hline the $t$ & No & 66.4 & 18.1 & 54.9 & 27.0 & \\
\hline In the summer the ground or flooring that lactating cows stand on was dry most & Yes & 51.1 & 24.3 & 51.8 & 23.9 & 0.0331 \\
\hline of the time & No & 48.9 & 18.3 & 52.7 & 29.0 & \\
\hline During the last 12 months, some cows drank from a single cup/bowl waterer & Yes & 43.8 & 28.3 & 48.1 & 23.6 & $<0.0001$ \\
\hline used & No & 56.2 & 15.9 & 55.5 & 28.6 & \\
\hline During the last 12 months, some cows drank from a single cup/bowl waterer & Yes & 7.8 & 30.4 & 45.6 & 24.0 & 0.1220 \\
\hline used by one cow only & No & 92.2 & 20.6 & 52.8 & 26.6 & \\
\hline During the last 12 months, some cows drank from a water tank or trough & Yes & 93.6 & 20.6 & 52.8 & 26.6 & 0.0823 \\
\hline (covered or & No & 6.4 & 32.3 & 44.6 & 23.1 & \\
\hline Biosecurity & & & & & & \\
\hline Cattle (calves, heifers, cows, or bulls) were brought onto the operation during & Yes & 55.9 & 17.0 & 54.2 & 28.8 & 0.0007 \\
\hline 2001 & No & 44.1 & 26.7 & 49.9 & 23.4 & \\
\hline
\end{tabular}


Table 1 (Continued). Herd management variables associated $(P<0.15)$ with dairy cow mortality by univariate analysis of data from 953 operations in 21 states

\begin{tabular}{|c|c|c|c|c|c|c|}
\hline Variable description & Level & $\begin{array}{l}\text { Herds } \\
(\%)\end{array}$ & \multicolumn{3}{|c|}{ Herds by mortality $(\%)$} & $\chi^{2} P$-value \\
\hline \multirow{3}{*}{$\begin{array}{l}\text { Percent of the herd composed of bred dairy heifers, lactating dairy cows, or dry } \\
\text { dairy cows brought onto the operation during } 2001(\%)\end{array}$} & $>27.7$ & 8.9 & 12.2 & 55.6 & 32.2 & \multirow[t]{3}{*}{0.0003} \\
\hline & $0.1-5.5$ & 11.5 & 12.1 & 54.3 & 33.6 & \\
\hline & 0 & 59.1 & 26.2 & 51.2 & 22.6 & \\
\hline \multirow{2}{*}{$\begin{array}{l}\text { Dairy cows, dairy heifers, or their feed had some physical contact with deer or } \\
\text { other members of the deer family (such as elk, moose, etc.) }\end{array}$} & Yes & 45.1 & 25.9 & 48.8 & 25.3 & \multirow[t]{2}{*}{0.0051} \\
\hline & No & 54.9 & 17.5 & 55.2 & 27.3 & \\
\hline \multirow[t]{2}{*}{ Dairy cows, dairy heifers, or their feed had some physical contact with dogs } & Yes & 65.5 & 23.0 & 49.1 & 27.9 & \multirow{2}{*}{0.0190} \\
\hline & No & 34.5 & 18.1 & 58.3 & 23.6 & \\
\hline \multirow[t]{2}{*}{ During the last $12 \mathrm{mo}$, some cows drank from a lake, pond, stream, river, etc. } & Yes & 31.3 & 25.7 & 50.2 & 24.1 & \multirow[t]{2}{*}{0.0667} \\
\hline & No & 68.7 & 19.3 & 53.3 & 27.4 & \\
\hline
\end{tabular}

weighted ordinal logistic model (Table 2). There were no significant interactions between variables in the final model. Model results indicated that the odds of a herd having a greater level of mortality were 2.75 times as high among herds with a high percentage $(>3.4 \%)$ of respiratory problems during 2001, and 1.71 times as high among herds with a moderate level $(0.1$ to $3.4 \%)$ of respiratory problems compared with herds with no documented $(0 \%)$ respiratory problems (Table 2). The odds of a herd being in a higher category of dairy cow mortality were 2.89 times as high among herds with a high percentage $(>16.1 \%)$ of lameness during 2001 , and 2.34 times as high among herds with a moderate level (3.4 to 16.1\%) of lameness compared with herds with a low level $(\leq 3.3 \%)$ of lameness. Further, the odds of a herd being in a higher category of dairy cow mortality were 2.27 times as high among herds with a high percentage $(>41.2 \%)$ of sick cows treated at least once with antibiotics during the preceding $12 \mathrm{mo}$, and 1.61 times as high among herds with a moderate level (12.8 to $41.2 \%)$ of sick-cow treatments compared with herds with a lower level $(\leq 12.7 \%)$ of sick animals treated with antibiotics.

Herds with a low percentage of cows that were culled less than 50 DIM $(\leq 2.0 \%)$ were 1.97 times more likely to have a greater level of mortality than were herds with a moderate level (2.1 to 20.8\%) of cows that were culled less than 50 DIM. The odds of a herd being in a

Table 2. Multivariate analysis of risk factors for high levels of dairy cow mortality on US dairies $(n=953$ farms)

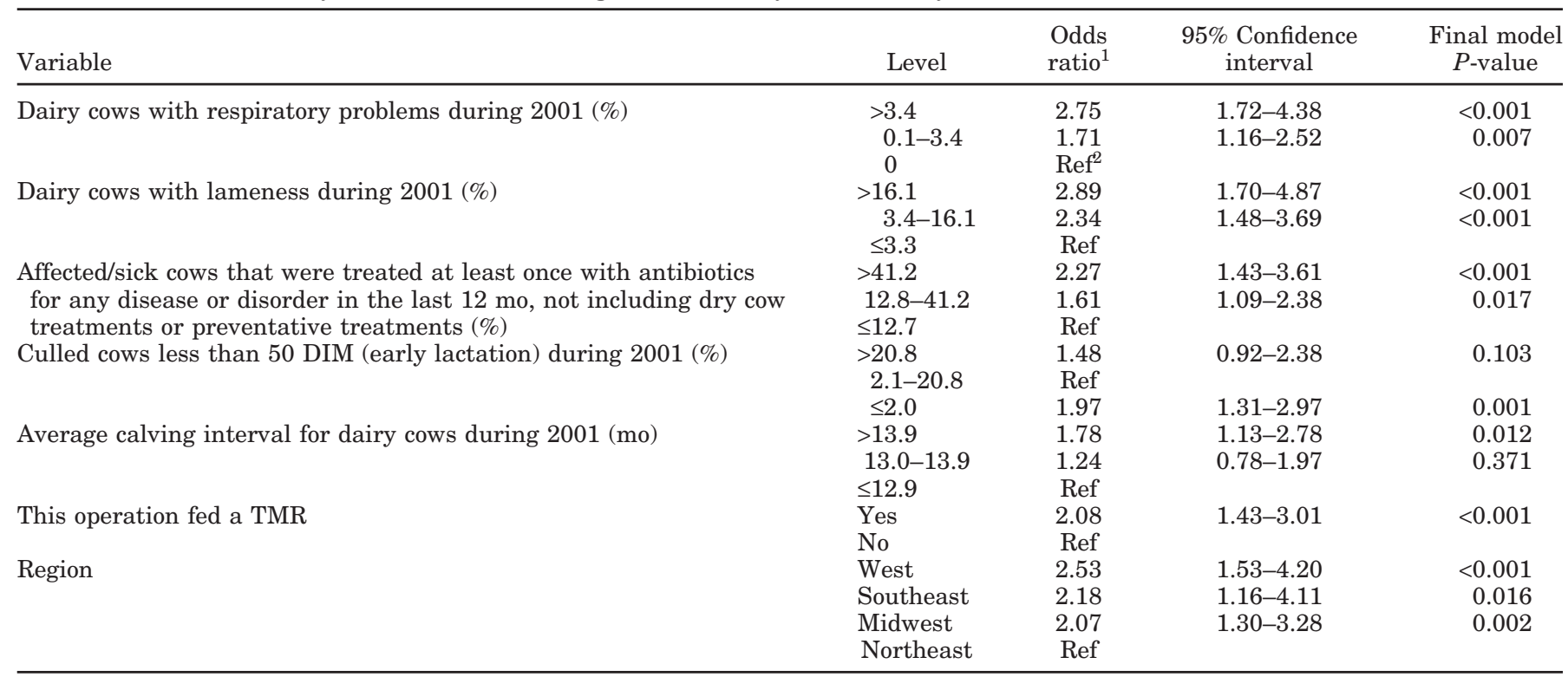

${ }^{1}$ Odds of having a greater mortality level.

${ }^{2}$ Reference category. 
higher category of dairy cow mortality were 1.78 times as high among herds with a longer (>13.9 mo) calving interval compared with herds with a shorter $(\leq 12.9 \mathrm{mo})$ calving interval. Herds fed a TMR were 2.08 times more likely to have a greater level of mortality than were herds that did not feed a TMR. Additionally, herds located in the West, Southeast, and Midwest were respectively $2.53,2.18$, and 2.07 times more likely to experience a greater level of dairy cow mortality than were herds in the Northeast.

\section{DISCUSSION}

The national scope of the sampling including information regarding management practices and characteristics of dairy production provided this current study with a unique data set. There are relatively few studies focusing on dairy cow mortality (Gardner et al., 1990; Faye and Perochon, 1995; Stevenson and Lean, 1998; Norgaard et al., 1999; Thomsen et al., 2004, 2006; Thomsen and Houe, 2006). A primary focus has often been on describing mortality relative to population characteristics such as parity, disease prevalence, or days in lactation while attempting to specify causes of death.

Some studies have, however, focused on management factors and their relationships to dairy cow mortality (Norgaard et al., 1999; Smith et al., 2000; Thomsen et al., 2006). An increase in herd size, average SCC, or the proportion of purchased cows has been shown to result in an increasing mortality risk at the herd level. Lower mortality risks have been found for herds that were pasture-grazed during the summer, organic versus conventional, used freestall barns with deep litter, or had increasing milk production at the herd level (Smith et al., 2000; Thomsen et al., 2006). Others have suggested that although larger herd sizes with increased mechanization contribute to less attention per cow and increased mortality, greater levels of physiologic stress and increased mortality can also stem from key production figures such as increasing concentrate consumption and average milk yield per cow (Norgaard et al., 1999).

In the present study, univariate associations were demonstrated between greater mortality levels and increasing herd size, dairy location, production parameters related to nutritional and health management, specific disease problems and treatments, facilities, and biosecurity. Contrary to previous reports, this study found that herds with greater annual rolling herd averages for milk production were more likely to be associated with greater mortality levels than were the lowestproducing herds. The final multivariate model retained factors associated with management as well as health and reproductive problems. Specifically, the final model demonstrated increased odds of a greater level of mortality when a TMR was fed, and for those operations with the lowest level of culled cows less than 50 DIM, the longest calving interval level, or increased levels of respiratory problems, lameness, or antibiotic treatments of sick cows.

Greater rates of common production diseases are often related to an increase in mortality (Norgaard et al., 1999; Thomsen et al., 2007). A large proportion of dairy cow deaths (Stevenson and Lean, 1998; Thomsen et al., 2004) and the greatest frequency of health disorders are associated with early lactation, including locomotor disorders that may result in euthanasia (Shanks et al., 1981; Markusfeld, 1993; Green et al., 2002). If homeostatic mechanisms cannot respond to the tremendous metabolic and endocrine challenges related to parturition and the onset of lactation, diseases such as clinical hypocalcemia, ketosis, retained fetal membranes, metritis, mastitis, and abomasal displacement may occur. Diseases such as laminitis, ovarian cysts, endometritis, and anestrus that typically become clinically apparent later postpartum are related to this early postpartum period as well (Melendez and Risco, 2005). Failing to recognize and appropriately manage or remove those animals suffering from severe disease and disorders during early lactation may be at the expense of increased mortality levels. Factors within the final model that were associated with dairy cow mortality included variables representing herd reproduction, disease recognition and treatment, and early postpartum culling, highlighting the influence and importance of the transition period on the health and productivity of dairy cows.

The calving interval for a dairy represents numerous facets of an operation's herd and reproductive health and management indices. Herd size and calving interval have been positively correlated (USDA, 2002a) and the shift toward larger dairies has created a new management paradigm (Lucy, 2001). Complex interactions between variables such as dairy expansion and labor management, disease control within confinement dairies, inbreeding and selection for production traits, hormonal manipulation, and heat abatement dictate calving intervals (Pryce et al., 2000; Lucy, 2001) and mirror the interwoven physiologic and management factors that potentially determine mortality rates.

Economic pressure drives the structural development of dairy farming and has necessitated the intensification of production through the comprehensive rationalization of production systems alongside productivity increases (Norgaard et al., 1999). Intensive management practices such as animal crowding and feeding high levels of concentrate may contribute to greater levels of physiological stress. These practices in tandem with 
changes in the physical environment (increased mechanization, larger herd sizes) that contribute to less attention per cow, altered culling practices, and an influx of purchased cows may adversely influence death rates (Norgaard et al., 1999; Weigel et al., 2003; Thomsen et al., 2006). For large, intensively managed herds, training and oversight of employees becomes increasingly important. The ability of dairy personnel to adequately identify disease in individual animals and respond with prompt, appropriate individual animal attention is limited by the extent of their experience and training (Ruegg, 2001). Because the preponderance of sick cows on large dairies are identified, diagnosed, and treated by farm workers with limited training, increased health problems and deaths may be associated with inadequate training and subsequent inadequate clinical disease management or animal removal.

Variations in regional US death losses have been described previously (Smith et al., 2000). This association may relate to regional differences in aspects of the physical environment, nutrition, and management factors. After adjusting for other factors, this study demonstrates that herds located in the West, Southeast, and Midwest experienced a significantly greater level of dairy cow mortality than did herds in the Northeast. One of the most striking facets of regional dairy production involves the trend for herd expansion at the expense of farm numbers. Increases in disease-related problems as a function of inadequate biosecurity have been documented following herd expansions (Faust et al., 2001). Additionally, increases in physiological strain as well as a more stressing environment following expansion (Norgaard et al., 1999; Weigel et al., 2003) may limit the resistance of cattle when exposed to infectious agents (Thomsen et al., 2006). Regional variations in mortality levels may relate to problems associated with dairy herd expansion.

The goal of this analysis was to identify features of dairy operations that might be managed differently to decrease mortality rates. The Dairy 2002 survey was not specifically designed to assess causes of mortality, and therefore it should be expected that some of the identified associations with mortality would not be as well focused as desired. The univariate analysis demonstrated associations between greater mortality levels and numerous health management variables describing the administration of vaccinations and nutritional supplementation. Rather than implying that vaccination or vitamin and mineral supplementation causes mortality, it is more likely that operations confronted with animal health challenges incorporate such management strategies. Similarly, variables such as respiratory disease and lameness were strongly associated with dairy mortality, but this observation does not sub- stantiate that these conditions cause greater levels of mortality. It is more plausible that some management features not specifically identified with this data set promote both high levels of dairy cow health challenges and high levels of dairy mortality. Future studies should attempt to identify specific features of intensified dairy production and management likely to adversely influence cow health and survival.

\section{CONCLUSIONS}

Dairy cow mortality is an increasing problem in the dairy industry. Analysis of a variety of herd characteristics and practices at the national level suggests that health problems in tandem with physical and management changes related to intensification are predictors of mortality. When analyzing causes of dairy cow mortality, consideration should be given to operational attributes such as the use and composition of a total mixed ration, the calving interval, region of the country, and herd levels of respiratory disease, lameness, sick cow treatments, and early postpartum culling.

\section{REFERENCES}

Dechow, C. D., G. W. Rogers, U. Sander-Nielsen, L. Klei, T. J. Lawlor, J. S. Clay, A. E. Freeman, G. Abdel-Azim, A. Kuck, and S. Schnell. 2004. Correlations among body condition scores from various sources, dairy form, and cow health from the United States and Denmark. J. Dairy Sci. 87:3526-3533.

Dematawewa, C. M., and P. J. Berger. 1998. Genetic and phenotypic parameters for 305-day yield, fertility, and survival in Holsteins. J. Dairy Sci. 81:2700-2709.

Dohoo, I. R., and S. W. Martin. 1984. Disease production and culling in Holstein-Friesian cows III Disease and production as determinants of disease. Prev. Vet. Med. 2:671-690.

Faust, M. A., M. L. Kinsel, and M. A. Kirkpatrick. 2001. Characterizing biosecurity, health, and culling during dairy herd expansions. J. Dairy Sci. 84:955-965.

Faye, B., and L. Perochon. 1995. Mortality of dairy cows in an ecopathological survey in Brittany / La mortalite des vaches laitieres dans l'enquete ecopathologique Bretagne. Vet. Res. 26:124-131.

Gardner, I. A., D. W. Hird, W. W. Utterback, C. Danaye-Elmi, B. R. Heron, K. H. Christiansen, and W. M. Sischo. 1990. Mortality, morbidity, case-fatality, and culling rates for California dairy cattle as evaluated by the National Animal Health Monitoring system, 1986-87. Prev. Vet. Med. 8:157-170.

Green, L. E., V. J. Hedges, Y. H. Schukken, R. W. Blowey, and A. J. Packington. 2002. The impact of clinical lameness on the milk yield of dairy cows. J. Dairy Sci. 85:2250-2256.

Lucy, M. C. 2001. Reproductive loss in high-producing dairy cattle: Where will it end? J. Dairy Sci. 84:1277-1293.

Mallard, B. A., J. C. Dekkers, M. J. Ireland, K. E. Leslie, S. Sharif, C. L. Vankampen, L. Wagter, and B. N. Wilkie. 1998. Alteration in immune responsiveness during the peripartum period and its ramification on dairy cow and calf health. J. Dairy Sci. 81:585595.

Markusfeld, O. 1993. Parturition disease complex of the high-yielding dairy cow. Acta Vet. Scand. Suppl. 89:9-15.

Melendez, P., and C. A. Risco. 2005. Management of transition cows to optimize reproductive efficiency in dairy herds. Vet. Clin. North Am. Food Anim. 21:485-501.

Milian-Suazo, F., H. N. Erb, and R. D. Smith. 1989. Risk factors for reason-specific culling of dairy cows. Prev. Vet. Med. 7:19-29. 
NAHMS. 1997. Beef '97, Parts I and II: Reference of 1997 Beef Cow/ Calf Health and Management Practices. Report from USDA:APHIS:VS, National Animal Health Monitoring System, Fort Collins, CO.

Norgaard, N. H., K. M. Lind, and J. F. Agger. 1999. Cointegration analysis used in a study of dairy-cow mortality. Prev. Vet. Med. 42:99-119.

Piccinini, R., E. Binda, M. Belotti, G. Casirani, and A. Zecconi. 2004 The evaluation of non-specific immune status of heifers in field conditions during the periparturient period. Vet. Res. 35:539-550.

Politis, I., N. Hidiroglou, J. H. White, J. A. Gilmore, S. N. Williams, H. Scherf, and M. Frigg. 1996. Effects of vitamin E on mammary and blood leukocyte function, with emphasis on chemotaxis, in periparturient dairy cows. Am. J. Vet. Res. 57:468-471.

Pryce, J. E., M. P. Coffey, and S. Brotherstone. 2000. The genetic relationship between calving interval, body condition score and linear type and management traits in registered Holsteins. J. Dairy Sci. 83:2664-2671.

Ruegg, P. L. 2001. Health and Production Management in Dairy Herds. Pages 211-254 in Herd Health: Food Animal Production Medicine. 3rd ed. O. M. Radostits, ed. W.B. Saunders, Philadelphia, PA.

Shanks, R. D., A. E. Freeman, and F. N. Dickinson. 1981. Postpartum distribution of costs and disorders of health. J. Dairy Sci. 64:683-688

Smith, J. W., L. O. Ely, and A. M. Chapa. 2000. Effect of region, herd size, and milk production on reasons cows leave the herd. J. Dairy Sci. 83:2980-2987.

Stevenson, M. A., and I. J. Lean. 1998. Descriptive epidemiological study on culling and deaths in eight dairy herds. Aust. Vet. J. $76: 482-488$.
Thomsen, P. T., and H. Houe. 2006. Dairy cow mortality. A review. Vet. Q. 28:122-129.

Thomsen, P. T., A. M. Kjeldsen, J. T. Sorensen, and H. Houe. 2004. Mortality (including euthanasia) among Danish dairy cows (1990-2001). Prev. Vet. Med. 62:19-33.

Thomsen, P. T., A. M. Kjeldsen, J. T. Sorensen, H. Houe, and A. K. Ersboll. 2006. Herd-level risk factors for the mortality of cows in Danish dairy herds. Vet. Rec. 158:622-626.

Thomsen, P. T., S. Ostergaard, J. T. Sorensen, and H. Houe. 2007. Loser cows in Danish dairy herds: Definition, prevalence and consequences. Prev. Vet. Med. 79:116-135.

Tsuruta, S., I. Misztal, and T. J. Lawlor. 2005. Changing definition of productive life in US Holsteins: Effect on genetic correlations. J. Dairy Sci. 88:1156-1165.

USDA. 2000. Part I: Baseline Reference of Feedlot Management Practices, 1999. Report from USDA:APHIS:VS, CEAH, National Animal Health Monitoring System. Fort Collins, CO.

USDA. 2002a. Dairy 2002, Part I: Reference of Dairy Health and Management in the United States, 2002. Report from USDA:APHIS:VS, CEAH, National Animal Health Monitoring System. Fort Collins, CO.

USDA. 2002b. Dairy 2002, Part III: Reference of Dairy Cattle Health and Health Management Practices in the United States, 2002. Report from USDA:APHIS:VS, CEAH, National Animal Health Monitoring System. Fort Collins, CO.

Weigel, K. A., R. W. Palmer, and D. Z. Caraviello. 2003. Investigation of factors affecting voluntary and involuntary culling in expanding dairy herds in Wisconsin using survival analysis. J. Dairy Sci. 86:1482-1486.

Wenz, J. R., G. M. Barrington, F. B. Garry, K. D. McSweeney, R. P. Dinsmore, G. Goodell, and R. J. Callan. 2001. Bacteremia associated with naturally occuring acute coliform mastitis in dairy cows. J. Am. Vet. Med. Assoc. 219:976-981. 